\title{
BUILDING LEADERSHIP SKILLS THROUGH HIGH-IMPACT EXPERIENCES
}

\section{Abstract}

The Organizational Leadership class is a staple in most undergraduate and graduate management curricula. Faculty teaching leadership courses recognize the need for experiential learning, but often struggle to find meaningful and manageable learning opportunities. Based on the high-impact practices of service and community-based learning, we offer three high-impact experiences designed to complement an organizational leadership course. These experiences utilize experiential learning to reinforce the critical leadership skills of demonstrate empathy, professional networking, and lifelong self-development. These experiences, coupled with self-reflection, enable students to grow their leadership capability while building demonstrable professional skills.

\section{Introduction}

The effectiveness of management education in colleges of business has been scrutinized for nearly as long as formal business education has been practiced (Lamb et al., 2020). It is clear to most management educators that traditional classroom learning is insufficient, and that skill building through experiential learning methods is imperative to growing confident, capable, and career-ready graduates (Reid et al., 2020). Leadership is an essential managerial skill, which business school graduates often lack as they enter early-career managerial roles (Osmani et al., 2019). We have developed a series of high-impact, out-of-class experiences to enhance a traditional organizational leadership course by encouraging growth in important student leadership skills.

\section{Leadership Skills}

In the 2018 National Association of Colleges and Employers (NACE) career-readiness report, 73\% of employers rated leadership as an essential skill for entry-level college graduates, while only $33 \%$ felt that the college graduates they hired were minimally proficient in leadership (Koc et al., 2018). NACE defined leadership as,

The ability to leverage the strengths of others to achieve common goals and use interpersonal skills to coach and develop others. The individual is able to assess and manage his/her emotions and those of others; use empathetic skills to guide and motivate; and organize, prioritize, and delegate work. (Career Readiness Defined, n.d., para. 5)

Management educators also recognize the presence of a leadership-skills gap within the business curriculum, resulting from heavy emphasis on analytic skills at the 
expense of softer skills such as leadership (Van Buren \& Hood, 2010; Pfeffer \& Fong, 2002).

\section{Which Soft Skills are Necessary for Effective Leadership?}

Robert Katz (1955) was among the first to argue that effective managers must possess a specific set of skills. In a survey of 332,860 employees, Zenger \& Folkman (2009) found that leaders need a variety of analytic and soft skills, and that the relative importance of those skills changes little based on organizational level. More than ever, early-career managers are expected to arrive to new roles ready to connect with and inspire others, build relationships and grow their network, and take charge of their own career and professional development. Unfortunately, recent graduates are falling far short of expectations in most of these areas (Koc et al., 2018). Increasing emphasis on the development of leadership skills improves the marketability and job readiness of students. We focus on the following three critical leadership skills: demonstrate empathy, professional networking, and lifelong self-development.

Demonstrate Empathy. Empathy is understanding another person's experience by imagining oneself in that experience as if it were being experienced by the self (Hodges \& Myers, 2007), or simply the ability to feel the way someone else feels (Hoffman, 2000). Empathy is fundamental to authenticity and genuineness in leadership roles (Holt et al., 2017). Empathy enables other interpersonal skills and is requisite for the skills identified as most important by Zenger and Folkman (2009), including inspire and motivate others, build relationships, and communicate powerfully. Studies of transformational leaders have found that those who demonstrate genuine concern for others increase employee achievement, motivation, and job satisfaction, while reducing felt stress (Alban-Metcalfe \& Alimo-Metcalfe, 2000). The genuine concern for others element of transformational leadership has been referred to as 'empathy with action' in some studies (e.g., Miller, 2009). By demonstrating empathy, managers improve interpersonal communication, promote inclusivity and cohesion, and can better understand employee perceptions and behaviors, leading to more effective leadership.

Professional Networking. Networking is extraprofessional behavior consisting of socializing and engaging in intra- and inter-organizational politics (Reinholt et al., 2011). Managers who engage in high levels of networking behaviors are more successful than managers who do not, likely because of increased access to resources and opportunities afforded them by their expanded pool of sociopolitical exchange partners (Luthans, 1988). Two of the leadership skills identified as essential by Zenger and Folkman (2009) are reflective of networking behavior, builds relationships and connects the group to the outside world. Research supports the positive effect managerial networking behaviors have on the survival and economic output of organizations (Powell \& Smith-Doerr, 1994).

Self-development. Preparing students with the skills required for lifelong learning and selfdirected growth, i.e. life beyond the classroom, is one of the most essential and neglected aspects of contemporary education (Chickering, 1994). In this new career environment, upward career progression in a single organization is becoming more rare and self-development and career management are becoming more valuable (Robson \& Hansson, 2007). It is imperative that students are taught where and how to pursue continuing education, as well as experience first-hand the value and necessity of doing so.

\section{Leadership Education}

Over the last decade, the topic of leadership education within universities has received 
significant attention. For example, in two prominent management education journals, Academy of Management Learning and Education and the Journal of Management Education, the word leadership appears in the title of published papers an average of 4.5 and 2.7 times annually. The popularity of leadership as a topic of higher education journals is unsurprising given that universities view the creation of leaders as fundamental to their mission (Pfeffer, 2011).

Most educators agree that leadership, to some degree, can be taught, and that classroom instruction can play some part in guiding that learning (Doh, 2003). Nearly all agree that classroom learning is insufficient, and must be reinforced with experiential learning (Buchanan, 2017; Wildermuth et al., 2015). At its best, a university education serves as a spark and incubator for leadership development, but development is a lifelong process that educators can only influence in short bursts. Petriglieri and DeRue captured that sentiment when introducing the Academy of Management virtual collection on leadership development in business schools,

Leaders are not the finished product of any single institution. Learning for leadership lasts a lifetime. The question instead is how business schools best contribute their students' ongoing development as leaders. That means asking how to help them acquire knowledge and skills; stimulate personal reflection and clarification; facilitate understanding of, and connection with, communities that may affect and be affected by their leadership; and, most importantly, reinforce the habit of lifelong learning. (n.d., para. 5)

While there is general agreement on the need for experiential learning to develop leaders, there exists little guidance about the nature of those experiences and the role of the leadership course in facilitating learning. Next, we will discuss drawbacks of the most common experiential learning approach in university leadership education, the case method, and then propose an experiential learning system appropriate for graduate and undergraduate students designed around the core leadership skills previously identified.

Case Learning. Case learning has long been used by the world's best business schools to connect course content to leadership practice (Foster \& Carboni, 2008). In case learning exercises, students generally form teams to examine real-world problems, formulate solutions, and examine their problemsolving processes in a Socratic discussion led by the instructor. Criticisms of case learning have centered on two basic issues, both of which are especially problematic when applied to learning leadership skills.

First, cases often lack the complexity and ambiguity of real-world leadership challenges. Cases are specifically and carefully crafted to guide students through well-practiced analysis such that they reach a predetermined set of conclusions. Indeed, grading rubrics for case studies often examine both the process of reaching a conclusion and the accuracy of the conclusion reached. Herein lies the great paradox of the case methodology for teaching leadership. Leadership is about challenging the status quo and pursuing change in response to dynamic environments, while cases are teaching students to apply extant knowledge to solve stable problems. We assert that cases are excellent tools for training technical skills, but insufficient for training leadership.

Second, case learning focuses on externalized challenges and does not enable students to examine their inner selves, a critical element in leadership education. An important and often overlooked element of leadership training within university classrooms is self-exploration. In Harvard Business Review's first-ever special issue, covering breakthrough leadership, the editor proclaimed that leadership's first commandment is to "know thyself" (Collingwood, 2001, p. 8). The importance of selfexploration, leading to self-discovery and ultimately self-awareness, has led some management educators to promote the university as an identity workspace: a place where leaders can experiment with, assess, 
and refine their identities as part of the education process (Petriglieri \& Petriglieri, 2010). The traditional lecture plus case methodology of most leadership courses does not encourage or enable self-discovery. Cases are external problems, whereby students try to mimic best practices. When solving these cases, students rarely, if ever, must rely on their personal value system, examine their morality, decide where and how to contribute their efforts, show empathy to those affected, live with consequences, or initiate a multitude of other leadership skills. In this area, case learning falls short as an experiential methodology for leadership training.

Effective leadership education can be considered a pedagogy of practice, whereby students learn effective leadership through doing (Priest \& Clegorne, 2015; Pfeffer and Fong, 2002). As Henry Mintzberg put it, "Learning occurs where concepts meet experiences through reflection" (Mintzberg \& Gosling, 2002, p. 66). Scholars have argued that leadership education needs less focus on the answers to business problems, and more focus on reflective learning and asking questions that challenge the status quo (Clegg \& Ross-Smith, 2003). Indeed, how many executives have lamented the unforeseen costs of poor decisions reached through the highlyrefined analysis of problems? We concur that leadership training requires finding opportunities for self-development, self-reflection, and the application of leadership skills (McCall, 1998).

High-impact Practices. In education, high-impact practices (HIP) are teaching and learning methods which have been extensively studied and determined to be highly effective in university settings (Kuh, 2008). Two such practices, service learning and communitybased learning, are experiential learning methods well-suited for leadership education. Service learning involves volunteerism in community service activities guided by specific academic goals, while communitybased learning involves interaction with community partners for student development. HIP demand that students spend a considerable amount of time and effort on a purposeful task outside of the classroom, accompanied by reflection and feedback as part of the classroom experience.

Effective service and community-based learning experiences require students to interact with diverse people, different from themselves, often putting the student in uncomfortable situations (Kuh, 2008). Students can try-out and reflect on different behavioral strategies in a low-stakes, trailand-error setting. These activities provide students with life-changing experiences, leading to a better understanding of self and confidence in their ability to make an impact on others and the world. Each new experience must be followed by purposeful reflection, allowing the student to assimilate old and new experiences and reframe his/her abstract conceptualization of the event in order to learn and prepare for future opportunities (Kolb \& Kolb, 2005; Kolb, 1984).

Service learning has been utilized as a methodology for developing ethical reasoning and communication skills in students (Sabbaghi et al., 2013; Blewitt et al., 2018). In one study, students who engaged in service leaning were significantly more likely to express empathy in reflective writing assignments than students who did not (Wilson, 2011). In each of these studies, direct interaction with others was an important factor in student development. Students who participated in HIP also reported high levels of personal and practical gain (Kuh, 2008). Utilizing outside organizations to enhance student learning simultaneously exposes the student to a wider variety of views, a more diverse set of people and experiences, and helps them begin to establish their personal and professional networks (Priest \& Clegorne, 2015).

Reflective learning is essential to the effectiveness of HIP (Kuk \& Holst, 2018). A 2010 study concluded that experiential learning coupled with reflective writing assignments were effective in increasing students' internalization of leadership concepts (Moore et al., 2010). Reflective learning helps students to develop critical thinking, as well as to see the personal value in experiences (Kilgo et al., 2015). Without adequate guided reflection, students might find service and 
community-based learning activities to be stressful and inane, due to a lack of familiarity and comfort with self-development (Parks, 2005). Effective use of HIP requires careful consideration and high levels of communication and transparency with students, enabling students see the tasks as a challenge rather than a threat (Buchanan, 2017; Galpin \& Whittington, 2009).

\section{Classroom Application}

We present a series of activities, based on Kolb's (1984) Experiential Learning Theory and Kuh's (2008) description of HIP, designed to supplement a lecturebased organizational leadership course. Multiple instructors have effectively employed these activities in both undergraduate and graduate business courses at two universities. The activities, referred to as high-impact experiences (HIE) to students, utilize service and community-based learning to introduce and reinforce key leadership skills. Each experience specifically outlines for the student which critical leadership skill it is designed to reinforce. While the assignments are fairly self-evident, we believe there are at least three important faculty considerations prior to utilizing this methodology in your own classroom.

First, it is essential to consider student readiness prior to any engaging in any form of student learning, but the importance of readiness is magnified when students will interact with external partners as representatives of the campus community (Bata et al., 2018). The experiential exercises provided here have been used effectively at the undergraduate and graduate level at two universities. In one instance, the student population was more traditional and the activities were better received and more effective among graduate students. Undergraduate students struggled to find meaning and saw the tasks as overly burdensome, seeking to complete them in as easy and convenient a way as possible. In the other instance, a high percentage of undergraduates were non-traditional, with business undergraduates averaging 32 years of age. Most worked full- or part- time. In this case, undergraduate students were able to recognize significant meaning, along with personal and professional development, in the assignments. We recommend reflection by faculty members about the readiness of their own students for the $\mathrm{HIE}$, as well as implementing the assignments one at a time over multiple semesters to determine student responses and challenges.

Second, the provided assignments are time intensive. We do not recommend attempting them in short terms (e.g., summer, 5-week, or 8-week terms). Faculty at commuter campuses or with a high percentage of full-time employed students may find significant challenges with the time requirements of the provided HIE. We have significant experience implementing these activities at a commuter campus where nearly all students work at least part-time and more than half work full-time. To overcome the time constraints, we have moved the leadership courses to a hybrid format and directly mapped the time required for the assignments to the out-of-class learning time in the hybrid model. If that is not possible on your campus, we have also found success in a traditionally configured class by narrowing the requirements (e.g., one professional association meeting, five hours of community service) and/or allowing students to choose two of the three activities.

Third, faculty should consider the resources available to students. When utilizing these activities at a rural or remote university, we coordinated suitable activities for groups of students due to the limited availability of partner organizations. We provide a list of no-cost options for each experience, considering that many of our current students have limited financial resources. We also provide a list of campus resources that may offer assistance in finding free activities or funding for professional development activities. As a final precaution, we examine student preparation papers for high-cost activities and activities for which a student or member rate is likely available, then follow up with those students to ensure that they are aware of their options. The following section, Student Instructions, includes the instructions as communicated directly to students. 
Accordingly, headings are part of the instructions and do not follow the heading outline of this manuscript.

\section{Student Instructions}

High-Impact Experiences (HIE) are out-of-class activities that enable students to broaden their social perspective, to self-reflect on what it means to be a leader, and to grow as people who are prepared to have an impact in their communities as citizens and professionals. To meet the requirements for this semester you must complete three HIE outside of class. Your grade will be based on turning in a total of four papers, including a single combined preparation paper and three reflection papers, in accordance with the instructions below.

Preparation Paper. A preparation paper is required to ensure that each student has a plan to make satisfactory progress toward completing the HIE within the semester. Preparation requirements for each HIE are described within the instructions for that experience. You are required to submit a single paper, not more than two single-spaced pages, in preparation for the three HIE. In your paper, describe your plan for completing the three HIE in accordance with the course schedule. It is strongly encouraged that you write your plan out in a narrative format, rather than as a series of bullet points, to ensure that you have conceptually integrated the pieces of your plan.

HIE One. The purpose of this assignment is to encourage and enable students to interact with leaders at the community level and to demonstrate leadership, empathy, compassion, patience, and caring within their own communities.

To complete this assignment, each student must volunteer 10 hours in a non-profit organization that provides services and/or resources to a disadvantaged population.

Examples of disadvantaged populations include:

- Homeless

- Physically or mentally disabled
- Victims of domestic violence

- Recovering addicts

The volunteer assignment must direct contact with disadvantaged persons by the student, and the organization must be a 510 (c)(3) federally recognized not-for-profit charitable organization.

Preparation Paper for HIE One. Describe the purpose and meaning of the assignment, as it relates to your chosen organization. Then describe your plan for completing the assignment. You should include, at a minimum:

- The organization in which you intend to volunteer

- The name/email of the volunteer coordinator and whether you have already made contact

- The day(s) of the week and time of day you are available to volunteer

- What role, position, or activity you expect to be engaged in

- The total number of hours you plan to complete

- The date you plan to complete those hours

- What you hope to get out of this assignment in terms of your personal development

Reflection Paper for HIE One. For HIE One, you should write a paper discussing the impact that the experience had on you. In doing so, discuss how the experience might enable you to be a better leader in your community and in your workplace going forward. The reflection paper is an opportunity for you to look back on the activity and consider its importance to your growth. Suggestions that may help to improve your writing include:

- Impactful encounters with individuals (e.g., customers, other volunteers, etc.)

- Changes in your perspective, thoughts, or prejudices about a group 
- Personal insights into how service can enable professionals to become better leaders

The focus should be on connectedness. Demonstrate a theme regarding how service, empathy, support, passion, etc. enable leader effectiveness and how you have connected that to your personal leadership philosophy.

Proof of Completion for HIE One. Many non-profit organizations already have forms to document community service hours. If that is the case, then please submit the provided form, appended to your reflection paper. If your organization does not provide a completion form, please ask the volunteer coordinator or another representative to send you an email documenting your service hours using their organizational email account.

HIE Two. The purpose of this assignment is to enable students to interact one-on-one with a leader in their community. The student should develop networking skills, improve their professional etiquette, and gain from the valuable personal insights of an experienced leader.

To complete this assignment, each student must connect with a senior leader, share a meal with that leader, engage the leader in meaningful discussion, and reflect on the experience.

Examples of senior leaders might include:

- Corporate executive or medium-sized and larger business owner

- Politician or appointed public servant

- High-ranking military officer

- Head coaches

- Head of church or senior clergy

- $\quad$ Not-for-profit CEO

Preparation Paper for HIE Two. Describe the purpose and meaning of the assignment, as it relates to the specific person or type of leader you hope to meet. Then describe your plan for completing the assignment. Include, at a minimum:
- The specific leader you plan to meet

- Have you contacted them, or how do you plan to do so?

- How you plan to invite them to a meal?

- Your logistic plan for the meal

- When do you expect to have this complete? What is your backup date?

- Where you plan to go? Where is the leader's office? Will it require a reservation?

- What you plan to wear: professional, business casual, casual?

- Who will pay?

- Your conversational plan for the meal

- What are you trying to accomplish?

- What are some questions you plan to ask to accomplish your goals?

- Your plan to follow-up with the leader

Reflection Paper for HIE Two. For HIE Two, you should write a paper discussing the impact that the experience had on you. In doing so, you should also discuss how mentorship and professional networking can enable your personal leadership development going forward. The reflection paper is an opportunity for you to look back on the activity and reflect. There are no specific requirements, but some suggestions that may help to improve your writing include:

- Key pieces of advice from the leader

- Answers from the leader to your questions which you found most impactful

- Personal insights into the value of networking, mentorship, or other related activities gained as a result of this experience

Proof of Completion for HIE Two. There is no set standard, but some proof will be required. Failure to do so will result in a reduction to your reflection paper grade. Please attach your proof to the reflection paper as an appendix and submit as a single document. 
Examples of proof of completion might include:

- Photo with the leader

- Email from the leader referencing past meeting

HIE Three. The purpose of this assignment is to demonstrate the value and importance of continuing education and self-development as part of a strategy of career management. This should help the student to start to recognize some of the activities required to become and continue as a competent professional. In doing so, the student should seek out and find resources for ongoing professional development, enhance their professional networking skills, and recognize the need for continuous self-development starting now and continuing throughout their careers. To complete this assignment, each student must attend at least two meetings of a professional organization, follow-up with at least three (3) contacts made at the meetings, and reflect on the experience. Examples of professional organizations and associations might include:

- Project Management Institute

- Society for Human Resource Management

- Small Business Development Center

- Chamber of Commerce

- American Marketing Association

- Toastmasters

These are national and international organizations, with local chapters. Google.com and Eventbrite.com are great tools for finding professional organizations that may meet your particular needs.

Preparation Paper for HIE Three. Describe the purpose and meaning of the assignment, as it relates to your chosen organization. Then describe your plan for completing the assignment. You should include, at a minimum:

The specific organization you want to participate in

- Do you plan to simply attend the meetings, to join, or are you already a member?

- What are the dates of the meetings that fit in the assignment due dates?

- Which meetings do you plan to attend?

- Is there a potential conflict - work, family, school?

- Does the meeting have a cost and can you pay for it?

What type of activity occurs at a meeting? If you do not know, how can you find out?

Do you have a strategy for networking at the meeting? Do you need to:

- Get there early?

- Stay late?

- Bring resumes, business cards, etc.?

How will you meet people at the meeting?

- Should you practice a personal introduction? Elevator pitch?

- What do you want to let people know about yourself?

- What will you talk about once you have someone's ear?

What do you plan to wear to the meeting?

- Business attire, business casual, casual?

- Are you sure you know what each of these means to that group?

What is your plan for following up with the three people you meet?

- Get a business card?

- Email, lunch meeting, tour of their office, handwritten note?

- What do you hope to get out of this assignment in terms of your personal development?

Reflection Paper for HIE Three. For HIE Three, you should write a paper discussing the impact that the 
experience had on you. In doing so, you should also discuss how the experience might enable you to be a better leader. The reflection paper is an opportunity for you to look back on the activity and reflect. There are no specific requirements, but some suggestions that may help to improve your writing include:

- Key pieces of career advice from individuals you encountered

- Insight into what it means to be a competent professional

- The relationship between professional competence and effective leadership

- Insight into the time, energy, effort, and mechanisms by which professionals maintain and enhance their leadership skills

- Personal insights into the value of networking and/or professional development

Proof of completion for HIE Three. There is no set standard, but some proof will be required. Failure to do so will result in a reduction to your Reflection Paper grade. Please attach your proof to the Reflection Paper as an appendix and submit as a single document. You will need to provide proof that you completed both parts:

1. Attended the meetings

2. Followed-up with three contacts

Examples of proof of completion might include:

Attended the meeting:

- $\quad$ Photo of you at the meeting

- $\quad$ Receipt

- Name badge, if handed out

Followed-up with three contacts

- A photocopy of the three business cards

- Copies of emails sent to or received from the contacts referencing the event

\section{Conclusion}

We have had remarkable success teaching leadership skills utilizing this approach. Responses from students and the broader campus community have been exceptionally positive. Students have secured full-time employment, internships, and lasting mentorships, while raising the visibility of the university. Many students start out insecure and afraid, but by semester's end most are grateful that they were forced out of their comfort zones and towards the next step in their professional development. We conclude with sample student comments and future research directions for the use of HIE for student leadership development.

Student Reactions. To our surprise, students in sections utilizing the HIE were more likely to leave detailed comments on the end-of-semester instructor evaluations. Often, these were exclamations of gratitude, discussions of the significant impact the activity had on the student, and discussions of the awareness the student gained of his/her own ability to make a difference in another's life. The following are representative student comments culled from reflection papers and end-of-semester ratings of instruction.

"My perspective on the homeless and recovering addicts has changed significantly. I honestly used to think that many were frauds, but now I understand it's more complicated. This experience exposed me people trying to recover and improve their lives, no different than what we're all doing. I now have respect for those trying to change because I believe it is never too late. As a leader this experience taught me to work hard and never give up on myself or others."

"Personally, the lunch with a leader was the hardest for me. I think negatively of myself and have a lot of social anxiety, making this one-on-one experience extremely challenging for me. When we actually met, everything was easy and went very smooth. After the initial introduction, I felt like I was in my element and was able to speak professionally and build rapport quickly. This experience has given me the confidence 
needed to approach and talk to senior leaders."

"In just an hour, I met with three very successful women. They gave me insight on what it means to be a competent professional, how to effectively manage time, and ways to continue my education to have a successful career. This experience taught me about the rewards that wait if I simply get out of my comfort zone."

Limitations and Future Directions. There are three areas of inquiry we believe could improve the integration of HIE into traditional leadership courses. First, our assessment of these HIE is based primarily on student reactions and instructor observation. Instructors implementing these or similar practices may consider a more comprehensive approach to assessment as outlined by the American Association of Colleges and Universities (Finley, 2019).

Second, the HIE occurred in the isolation of a single course, while developing leadership skills is a lifelong process. Future authors may examine how to better integrate experiences within a course with the holistic campus experience. An example is provided by University Council for Educational Administration (Orr et al., 2010). We propose that viewing experiences the same way educators view learning objectives, as nested within the university-college-program-majorcourse levels, a more comprehensive leadership development program could be developed within the college experience.

Finally, there is some question of the generalizability of our approach due, to our limited focus on organizational leadership skills using Western conceptualizations of leadership. Future researchers may examine the effectiveness of HIE for learning leadership skills in cross-cultural, highly diverse, or culturally divergent settings. The role of western views of leadership in collegiate leadership development efforts should be examined in more detail, as previous research has demonstrated that overreliance on Western views can have profound effects (Muenich \& Williams, 2013). Additionally, future researchers might examine the different types of leadership skills that may be needed for social and community leadership, as opposed to our current focus on developing leadership skills required within formal organizations. 


\section{References}

Alban-Metcalfe, R. J., \& Alimo-Metcalfe, B. (2000). The transformational leadership questionnaire (TLQ-LGV): A convergent and discriminant validation study. Leadership \& Organization Development Journal, 21(6), 280-296. https://doi.org/10.1108/01437730010343077

Bata, M., Cox-Lanyon, V., \& Davis, M. (2018). When a student's "right to fail" harms the university brand: How a lack of guidance in experiential learning affects university-organization relationships. Journal of Management Education, 43(1), 108-120. https://doi.org/10.1177/1052562918811873

Blewitt, J. M., Parsons, A., \& Shane, J. M. (2018). Service learning as a high-impact practice: Integrating business communication skills to benefit others. Journal of Education for Business, 93(8), 412-419. https://doi.org/10.1080/08832323.2018.1498315

Buchanan, J. L. (2017). Leadership development and experiential methodology: The impact on learning leadership. International Journal of Arts \& Science, 10(2), 587-594. ProQuest.

Chickering, A. W. (1994). Empowering lifelong self-development. NACADA Journal, 14(2), 50-53. https://doi. org/10.12930/0271-9517-14.2.50

Clegg, S. R., \& Ross-Smith, A. (2003). Revising the boundaries: Management education and learning in a postpositivist world. Academy of Management Learning \& Education, 2(1), 85-98. https://www.jstor.org/ stable/40214170

Collingwood, H. (2001). Leadership's first commandment: Know thyself. Harvard Business Review, 79(1), 8.

Doh, J. P. (2003). Can leadership be taught? Perspectives from management educators. Academy of Management Learning and Education, 2(1), 54-67. https://www.jstor.org/stable/40214166

Finley, A. (2019, November). A comprehensive approach to assessment of high-impact practices (Occasional Paper No. 41). National Institute for Learning Outcomes Assessment (NILOA). https://www.aacu.org/sites/ default/files/files/publications/accu_niloa_hips_pub_2019.pdf

Foster, P., \& Carboni, I. (2008). Using student-centered cases in the classroom. Journal of Management Education, 33(6), 676-698. https://doi.org/10.1177/1052562908328747

Galpin, T., \& Whittington, J. L. (2009). Creating a culture of candor in the leadership classroom. Journal of Leadership Education, 8(2), 10-19. https://doi.org/10.12806/V8/I2/AB2

Hodges, S., \& Myers, M. (2007). Empathy. In R. F. Baumeister \& K. D. Vohs (Eds.), Encyclopedia of Social Psychology (Vol. 1, pp. 297-298). Sage. http://dx.doi.org/10.4135/9781412956253.n179

Hoffman, M. L. (2000). Empathy and moral development: Implications for caring and justice. Cambridge University Press. https://doi.org/10.1017/CBO9780511805851

Holt, S., Marques, J., Hu, J., \& Wood, A. (2017). Cultivating empathy: New perspectives on educating business leaders. The Journal of Values-Based Leadership, 10(1), 1-25. https://doi.org/10.22543/0733.101.1173

Katz, R. L. (1955). Skills of an effective administrator. Harvard Business Review, 33(1), 33-42.

Kilgo, C. A., Sheets, J. K., \& Pascarella, E. T. (2015). The link between high-impact practices and student learning: Some longitudinal evidence. Higher Education, 69(4), 509-525. http://dx.doi.org/10.1007/s10734014-9788-z 


\section{References}

Koc, E. W., Koncz, A. J., Eismann, L., \& Longenberger, A. (2018). Job Outlook 2018. Bethlehem, PA: National Association of Colleges and Employers. https://www.naceweb.org/store/2017/job-outlook-2018/

Kolb, A.Y., \& Kolb, D. A. (2005). Learning studies and learning spaces: Enhancing experiential learning in higher education. Academy of Management Learning and Education, 4(2), 193-212. https://www.jstor. org/stable/40214287

Kolb, D. A. (1984). Experiential learning: Experience as the source of learning and development. PrenticeHall.

Kuh, G. D. (2008). High-impact educational practices: What they are, who has access to them, and why they matter. Washington, DC: Association of American Colleges and Universities. https://www.aacu.org/leap/ hips

Kuk, H., \& Holst, J. D. (2018). A dissection of experiential learning theory. Adult Learning, 29(4), 150-157. https://doi.org/10.1177/1045159518779138

Lamb, P., Hsu, S. W., \& Lemanski, M. (2020). A threshold concept and capability approach to the crosscultural contextualization of western management education. Journal of Management Education, 44(1), 101-120. https://doi.org/10.1177/1052562919851826

Luthans, F. (1988). Successful vs. effective real managers. The Academy of Management Executive, 2(2), 127132. https://www.jstor.org/stable/4164814

McCall, M. W. (1998). High flyers: Developing the next generation of leaders. Harvard Business School Press.

Miller, M. (2009). Transformational leadership behaviours and empathy with action. Transformation: An International Journal of Holistic Mission Studies, 26(1), 45-59. https://doi.org/10.1177/0265378809102176

Mintzberg, H., \& Gosling, J. (2002). Educating managers beyond borders. Academy of Management Learning and Education, 1(1), 64-76. https://www.jstor.org/stable/40214100

Moore, C., Boyd, B. L., \& Dooley, K. E. (2010). The effects of experiential learning with an emphasis on reflective writing on deep-level processing of leadership students. Journal of Leadership Education, 9(1), 36-52. https://doi.org/10.12806/V9/11/RF3

Muenich, J., \& Williams, J. (2013). Universally enforced attributes of leadership with current prevalent leadership theories taught at Texas A\&M University. NACTA Journal, 57(3a), 45-50. https://www.jstor.org/ stable/nactajournal.57.3a.45

Orr, M. T., O'Doherty, A., \& Barber, M. (2012). Designing purposeful and coherent leadership preparation curriculum: A curriculum mapping guide. University Council for Educational Administration. http://www. ucea.org/resource/curriculum-mapping-guide-2/

Osmani, M., Weerakkody, V., Hindi, N., \& Eldabi, T. (2019). Graduates employability skills: A review of literature against market demand, Journal of Education for Business, 94(7), 423-432. https://doi.org/10.1 080/08832323.2018.1545629

Parks, S. D. (2005). Leadership can be taught: A bold approach for a complex world. Harvard Business School Press. 


\section{References}

Petriglieri, G., \& DeRue, D. S. (n.d.) How can business schools develop leaders? Academy of Management. http://aom.org/DevelopLeaders/

Petriglieri, G., \& Petriglieri, J. (2010). Identity workspaces: The case of business schools. Academy of Management Learning and Education, 9(1), 44-60. https://doi.org/10.5465/amle.9.1.zqr44

Pfeffer J. (2011) Leadership development in business schools: An agenda for change. In: J. Canals (Ed.) The future of leadership development. Palgrave Macmillan IESE Business Collection. https://doi. org/10.1057/9780230295087_10

Pfeffer, J., \& Fong, C. T. (2002). The end of business schools? Less success than meets the eye. Academy of Management Learning \& Education, 1(1), 78-95. https://doi.org/10.5465/AMLE.2002.7373679

Powell, W. W., \& Smith-Doerr, L. (1994). Networks and economic life. In N. J. Smelser \& R. Swedberg (Eds.), The handbook of economic sociology (pp. 368-402). Princeton University Press. DOI: 10.17323/1726-32472003-3-61-105

Priest, K. L., \& Clegorne, N. A. (2015). Connecting to experience: High-impact practices for leadership development. New Directions for Student Leadership, 145, 71-83. https://doi.org/10.1002/yd.20125

Reid, A., Cook, J., Viedge, C., \& Scheepers, C. B. (2020). Developing management effectiveness: The nexus between teaching and coaching. The International Journal of Management Education, 18(1), 1-13. https:// doi.org/10.1016/j.jime.2019.100334

Reinholt, M., Pedersen, T., \& Foss, N. J. (2011). Why a central network position isn't enough: The role of motivation and ability for knowledge sharing in employee networks. Academy of Management Journal, 52(6), 1277-1297. https://www.jstor.org/stable/41413619

Robson, S. M., \& Hansson, R. O. (2007). Strategic self-development for successful aging at work. The International Journal of Aging and Human Development, 64(4), 331-359. https://doi.org/10.2190/Q303$171 \mathrm{U}-7686-8517$

Sabbaghi, O., Cavanagh, G. F., \& Hipskind, T. (2013). Service-learning and leadership: Evidence from teaching financial literacy. Journal of Business Ethics, 118(1), 127-137. https://doi.org/10.1007/s10551-012-1545-6

Van Buren, H. J., \& Hood, J. N. (2010). Building student competency to develop power and influence through social capital. Journal of Management Education, 35(5), 648-678. https://doi. org/10.1177/1052562910369554

Wildermuth, C., Smith-Bright, E., Noll-Wilson, S., \& Fink. A. (2015). Walking the razors edge: Risks and rewards for students and faculty adopting case in point teaching and learning approaches. Journal of Leadership Education, 14(2), 30-50. https://doi.org/10.12806/V14/I2/R3

Wilson, J. C. (2011). Service-learning and the development of empathy in US college students. Education Training, 53(2/3), 207-217. http://dx.doi.org/10.1108/00400911111115735

Zenger, J., \& Folkman, J. (2009). The extraordinary leader: Turning good managers into great leaders. McGraw-Hill. 